partly on the basis of the 1961 policy statements of the Science Masters' Association (SMA) and the Association of Women Science Teachers (AWST) (now merged into the Association for Science Education). Accommodation in the Oxford School was therefore provided for each of the three stages of science education in secondary schools described by the SMA and the AWST statements-two years of general science teaching in the introductory phase, three years of intermediate work leading to o-level and two or three years of advanced work. The Oxford School has a four form entry, and a total of about 800 boys. Allowance was made for six teaching periods a week of science in the introductory phase, three to four periods for each of chemistry, physies and biology in the middle school and seven periods for each of the three subjects in the sixth form. The proportion of time allotted to science under this scheme is higher than in most other schools, with the result that the science block is larger than is usual. Twenty-four boys per class was thought to be the best number for middle school science, so that flexibility can be maintained in the timetable, while fifteen was considered the optimum number for experimental work in the advanced stage. Mathematics classrooms have added to the size of the block.

Self-contained subject departments were provided for the school, following the wishes of the staff, but the bulletin suggests that better use might have been made of space if closer integration had been considered, particularly as the boundaries between science subjects are becoming more blurred. Stores and preparation rooms for different subjects which often provide similar facilities and apparatus could well be shared by laboratories of different disciplines. The design of the separate departments is described in detail in the bulletin.

As well as educational questions the group had definite technical objectives in view. The first was to test a dimensional control system proposed by Dr J. W. Harding of the Building Research Station in his paper "Co-ordination by Design Modules". The second was to develop a rapidly erected "dry" form of construction that can be used for a variety of ten-storey buildings. Further use of the lighting system PSALI (permanent supplementary artificial lighting of interiors), first applied by the group to rooms at Harris College, Preston, was the third objective. This system is designed to provide strong light during the day to compensate for lack of daylight, but at night provides a lower level of light throughout the room. The fourth intention of the group was to gain experience with a computer for processing the bill of quantities, and apply modern management techniques, such as network analysis, to the scheme.

The project was under way before even the preliminary conclusions of the Nuffield Science Teaching Project were published, and the bulletin admits that the Oxford block may not be the best answer for the Nuffield requirements, but the detail and ideas put forward in the bulletin will be of considerable value to those designing science buildings in schools.

\section{Advice from Harwell}

DESPTTE the admonitions of the Select Committee on Science and Technology, Harwell continues to diversify.
This time it will be lending its experience to engineering companies involved in the problems of heat transfer and fluid flow. In return for an annual fee of about $£ 1,000$, firms will receive reports on the design of equipment, and there will also be a consultation service available to individual firms. The Chemical Engineering and Process Division has for the last ten years been working on heat transfer and fluid flow in the design of nuclear plants, and has therefore come into repeated contact with many of the firms that have shown interest in the new service. As early as 1954, for example, APV collaborated with Harwell on the flow of thorium bismuthide through pipes. This history of co-operation doubtless explains the enthusiasm felt in industry for the new service. The Atomic Energy Authority has announced that there will be long-term support programmes of research into problems chosen in consultation with industry.

Perhaps about 10 per cent of Harwell's scientists are now engaged on projects which could be described, in the words of the select committee, as "not inextricably linked to the primary task" of the Atomic Energy Authority. Finding ways of filling in the spare time of vast nuclear establishments is not merely a British pastime. At Oak Ridge Laboratory, in the United States, for example, there are teams working on desalination and centrifuges for medical use, both areas already tackled at Harwell.

\section{Britain Sick}

Among the winter "epidemics" which have recently been spreading through Britain, influenza at least seems to be on the decline. But bronchial complications associated with the infection are still increasing and the red warning for extra available hospital beds is still on.

The virus which has been causing this latest outbreak is influenza virus $A 2$, which is very similar to that responsible for the pandemic in 1957 and for several outbreaks since then. Of the three types of influenza virus, $A, B$ and $C$, type $A$ is the most common cause of influenza in humans and is associated with the pandemics and serious epidemics, while type $B$ is usually associated with small outbreaks which are rarely extensive; type $C$ usually causes inapparent infections. Because the virus is not a new sub-type, it is thought that most people will have acquired immunity to infection, and that the existing vaccines which consist of recent strains of $A 2$ are likely to afford protection. The principal danger arises when one sub-type mutates to another as in the pandemies of 1891, 1918 and 1957 and the serious epidemics of 1946. The periodicity of outbreaks on a less extensive scale is usually related to the accumulation of susceptible individuals and the removal of immune ones by death.

Another RNA virus-respiratory syncytial (chimpanzee coryza agent)--has been identified as the cause of death of five infants in Walsall and two more infants have recently been admitted to hospital with the same infection. This virus, which usually causes minor respiratory infections in adults, may, however, be associated with bronchitis and broncho-pneumonia in children and is very widespread-infecting children within the first few months after birth. Furthermore, antibodies present in the serum do not always prevent 
re-infection. According to Dr H. G. Pereira of the National Institute for Medical Research, the prospects of an efficient killed vaccine are not very good and a lot of work remains to be done in developing an attenuated virus vaccine.

Thirteen babies have so far died from a bacterial infection, gastro-enteritis, caused by $E$. coli strain 0-128. Happily, there have been no new cases within the last few days. It now seems that the infection was not the sole cause of death in every case. The involvement of multiple drug resistance transfer is the most likely explanation of how the bacteria became resistant to eight of the eleven antibiotics which have been tested at the Middlesbrough labora. tory. The extrachromosomal element, $R$ factor, which is responsible for infectious drug resistance is transmitted by conjugation from a resistant bacterium, through a pilus to a sensitive strain which also becomes resistant. The transfer process is repeated from cell to cell and the normal process of cell division also contributes to the rate of spread of multiple resistance in a susceptible population. There has been a suggestion that a combination of drugs might be effective in combating the infection, but this has only been shown experimentally, and in vivo applications would not necessarily be successful because the pattern of resistance in different individuals varies. Adults do not seem to be similarly infected; they have probably developed resistance.

Although the strain of Salmonella causing typhoid in the borough of Ealing has not yet been named, the same strain has been isolated from three cases. So far, typhoid has been confirmed in two patients, and four people have given positive specimens but have no symptoms. $\AA$ spokesman at the Ealing Health Department said it was difficult to identify the original carrier of the infection.

\section{Mink in the Wild}

WiLD populations of mink and coypu, descended from animals which have escaped from fur farms, have been established in England for some years. In spite of vigorous eradication campaigns, the animals are still so numerous that the Ministry of Agriculture has now had extended for five years the legislation whereby occupiers of agricultural land are obliged to report sightings to the ministry. The regulations

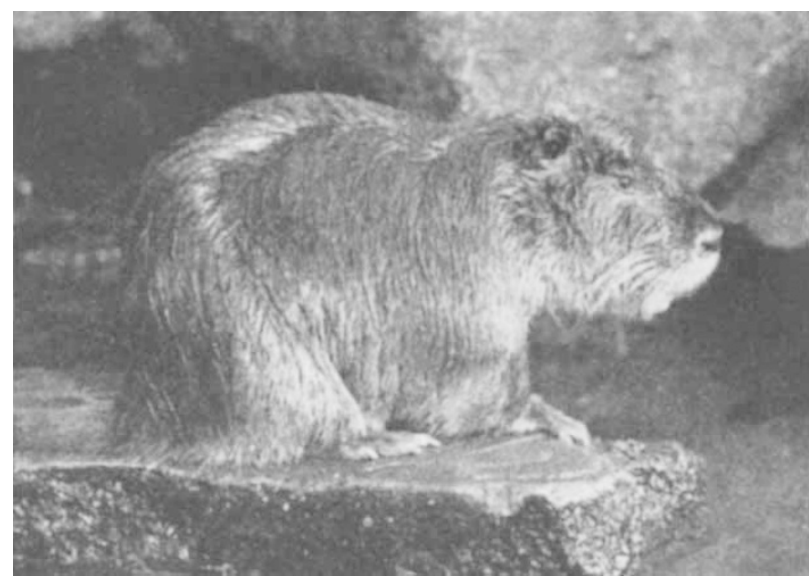

Coypu: 136,000 killed in three years. which govern the keeping and transporting of the animals also remain in force.

Coypus closely resemble beavers in appearance. Originally native to South America, they have been established in Suffolk and Norfolk since 1939. The damage they caused was largely compensated by their activity in keeping dykes and waterways free of weeds, and as long as they were worth trapping for their pelts their numbers remained within reasonable limits. But when coypu fur dropped out of fashion the population burgeoned and the damage done to crops such as sugar beet and by the burrows made in river banks reached significant proportions.

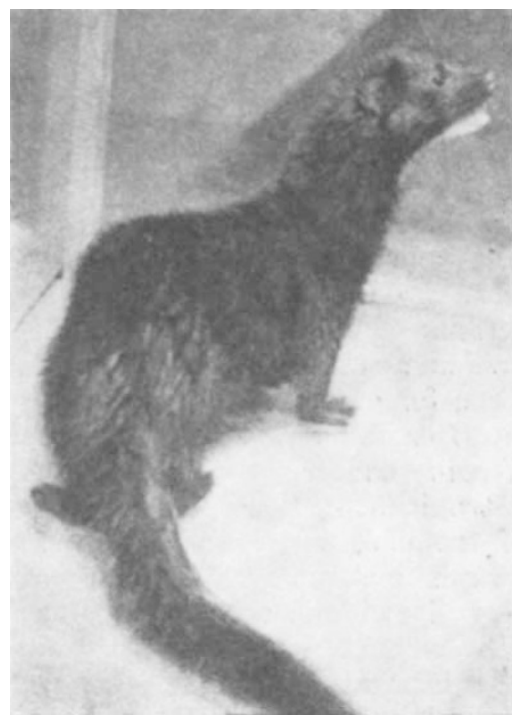

A thousand mink are trapped each year.

In 1962 a campaign was mounted to restrict coypus to a few sanctuaries in the Norfolk Broads, and by 1965136,000 animals had been killed.

Dr R. M. Newson of the Ministry of Agriculture's Infestation Control Laboratory estimates that the survivors of the campaign now number about 5,000 . Although a population of this order may be relatively harmless, rigorous control measures are still necessary because of the potential damage which could be caused by another population explosion. Not only have coypus developed a propensity for sugar beet over their usual diet of roots and weeds, but the undermining of dykes by their burrows, combined with high floods, could cause inestimable havoc. The population of wild mink has increased more slowly than that of coypu. Mink are members of the stoat and wcasel family and are native to North Ameriea. Wild mink have been established for some time and about 1,000 are trapped alive each year.

There appears to be room for disagreement on the precise amount of damage that mink do. The Ministry of Agriculture believes that wild mink are a potentially serious pest to fish, wild birds and poultry. Furbreeding experts, however, consider that frogs, mice and other economically worthless animals form the major part of their diet, and that mink may often be blamed for the depredations of other animals such as ferrets. But the Ministry is sufficiently convinced to have set up some 2,000 traps throughout the country. Mink fur, of course, still commands a considerable 